\title{
Striatal $\alpha 5$ Nicotinic Receptor Subunit Regulates Dopamine Transmission in Dorsal Striatum
}

\author{
Richard Exley, ${ }^{1}$ J. Michael McIntosh, ${ }^{2}$ Michael J. Marks, ${ }^{3}$ Uwe Maskos, ${ }^{4}$ and Stephanie J. Cragg ${ }^{1}$ \\ ${ }^{1}$ Department of Physiology, Anatomy, and Genetics, and Oxford Parkinson's Disease Centre, University of Oxford, Oxford OX1 3PT, United Kingdom, \\ ${ }^{2}$ Departments of Biology and Psychiatry, University of Utah, Salt Lake City, Utah 84132, ${ }^{3}$ Institute for Behavioral Genetics, University of Colorado, Boulder, \\ Colorado 80301, and ${ }^{4}$ Centre National de la Recherche Scientifique, Unité Neurobiologie Intégrative des Systèmes Cholinergiques, Institut Pasteur, 75724 \\ Paris Cedex 15, France
}

Polymorphisms in the gene for the $\alpha 5$ nicotinic acetylcholine receptor (nAChR) subunit are associated with vulnerability to nicotine addiction. However, the underlying normal functions of $\alpha 5$-containing nAChRs in the brain are poorly understood. Striatal dopamine (DA) transmission is critical to the acquisition and maintenance of drug addiction and is modulated strongly by nicotine acting at heteromeric $\beta 2$-containing $\left(\beta 2^{\star}\right)$ nAChRs. We explored whether $\alpha 5$ subunits, as well as $\alpha 4, \alpha 6$, and $\beta 3$ subunits, participate in the powerful regulation of DA release probability by $\beta 2^{*} \mathrm{nAChRs}$ in nucleus accumbens (NAc) core and in dorsal striatum [caudatoputamen $(\mathrm{CPu})$. We detected evoked dopamine release using fast-scan cyclic voltammetry at carbon-fiber microelectrodes in striatal slices from mice with deletions of $\alpha 4, \alpha 5, \alpha 6$, or $\beta 3$ subunits. We show that the nAChR subtypes that dominantly regulate dopamine transmission depend critically upon $\alpha 5$ subunits in the dorsal CPu in $\alpha 4 \alpha 5$ (non- $\alpha 6$ ) $\beta 2$-nAChRs but not in NAc core, where $\alpha 4 \alpha 6 \beta 2 \beta 3$-nAChRs are required. These data reveal the distinct populations of $n A C h R s$ that govern DA transmission in NAc core versus dorsal CPu. Furthermore, they indicate that $\alpha 5$ subunits are critical to the regulation of DA transmission by $\alpha 4 \beta 2^{\star} \mathrm{nAChRs}$ in regions of striatum associated with habitual and instrumental responses (dorsal $\mathrm{CPu}$ ) rather than pavlovian associations (NAc).

\section{Introduction}

There has been longstanding interest in the nicotinic acetylcholine receptor (nAChR) subtypes that participate in nicotine addiction. Receptors containing $\alpha 4$ and $\beta 2$ subunits are well known to be involved in nicotine's cellular and reinforcing effects. For example, deletion of either $\alpha 4$ or $\beta 2$ subunits prevents nicotineinduced changes in DA neuron excitability and nicotine selfadministration in rodents (Picciotto et al., 1998; Maskos et al., 2005; Pons et al., 2008). Recently, genome-wide association studies have identified that polymorphisms in $\mathrm{nAChR}$ genes in gene clusters for other subunits, $\alpha 5 / \alpha 3 / \beta 4$ and $\alpha 6 / \beta 3$, are associated with tobacco addiction (Thorgeirsson et al., 2008; Saccone et al., 2009; Bierut, 2010). Allelic variation and expression levels of $\alpha 5$ subunits have been particularly strongly associated, across independent studies (Saccone et al., 2009; Wang et al., 2009; Bierut, 2010). The $\alpha 5$ subunits, like $\beta 3$ subunits, are accessory subunits that are known to modify the properties of $\alpha 4$ - or $\alpha 6$-containing nAChRs respectively (Tumkosit et al., 2006; Grady et al., 2010; Kuryatov et al., 2011), but the roles of $\alpha 5$-containing $\left(\alpha 5^{\star}\right)$ or

Received Sept. 30, 2011; revised Jan. 4, 2012; accepted Jan. 4, 2012.

Author contributions: R.E., U.M., and S.J.C. designed research; R.E. performed research; J.M.M., M.J.M., and U.M. contributed unpublished reagents/analytic tools; R.E. analyzed data; R.E. and S.J.C. wrote the paper.

This work was supported by Medical Research Council UK Grant G0700932, Parkinson's UK Grant G1103, and NIH National Institute on Drug Abuse Grant P30 DA015663.

Correspondence should be addressed to Stephanie J. Cragg at the above address. E-mail: Stephanie.cragg@dpag.ox.ac.uk.

DOI:10.1523/JNEUROSCI.4985-11.2012

Copyright $\odot 2012$ the authors $\quad 0270-6474 / 12 / 322352-05 \$ 15.00 / 0$ $\beta 3^{\star} \mathrm{nAChRs}$ in normal brain function and in nicotine action in situ are poorly understood.

Recently, $\alpha 5^{\star} \mathrm{nAChRs}$ in the habenulo-interpeduncular pathway have been shown to regulate nicotine intake (Fowler et al., 2011; Frahm et al., 2011). However, nicotine dependence also critically involves striatal dopamine (DA). Mesostriatal DA neurons express a diverse array of subunits $(\alpha 3-7, \beta 2-4)$, and it has been suggested that up to six possible types of $\beta 2^{\star} \mathrm{nAChRs}$ are available in striatal DA axons for striatal ACh and nicotine to modulate DA transmission, namely, $\alpha 4 \beta 2, \alpha 4 \alpha 5 \beta 2, \alpha 4 \alpha 6 \beta 2 \beta 3$, $\alpha 4 \alpha 6 \beta 2, \alpha 6 \beta 2 \beta 3$, and $\alpha 6 \beta 2$ (Picciotto et al., 1998; Champtiaux et al., 2003; Exley and Cragg, 2008; Gotti et al., 2010; Exley et al., 2011). Striatal $\beta 2^{\star} \mathrm{nAChRs}$ respond to ACh released from striatal cholinergic interneurons to gate the dynamic probability of DA release and govern its sensitivity to the frequency of activity in DA axons (Zhou et al., 2001; Rice and Cragg, 2004; Zhang and Sulzer, 2004), which DA neurons change to signal information about reinforcers, or other salient stimuli and their cues (Schultz, 1998; Matsumoto and Hikosaka, 2009). It has been shown that the striatal $\mathrm{nAChRs}$ that regulate DA release probability differ in sensorimotor-associated striatum [caudatoputamen $(\mathrm{CPu})$ ] versus limbic-associated striatum [nucleus accumbens (NAc)], in particular that $\alpha 4$ (non- $\alpha 6) \mathrm{nAChRs}$ are dominant in $\mathrm{CPu}$ but $\alpha 4 \alpha 6^{\star}$ nAChRs are dominant in NAc (Exley et al., 2008, 2011). Since the $\mathrm{nAChR}$ subunit stoichiometries identified in striatum suggest that $\alpha 6^{\star}$ and $\alpha 5^{*} \mathrm{nAChRs}$ are mutually exclusive populations, these data suggest in turn that any function for $\alpha 5$ subunits in regulating DA release might also covary with striatal regions and be precluded in NAc. Here, by using mice with dele- 


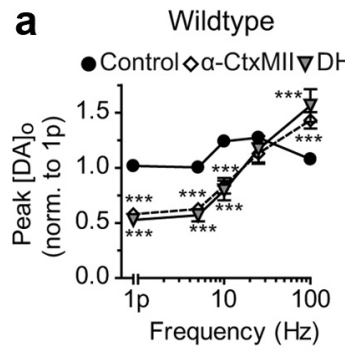

a4-/-

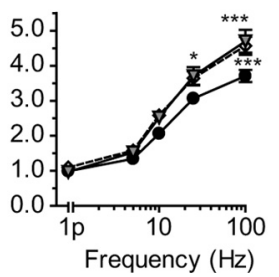

$\alpha 6-/-$

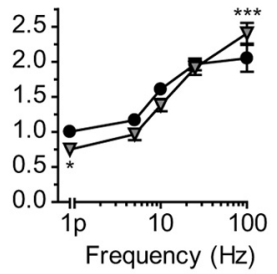

a5-/-

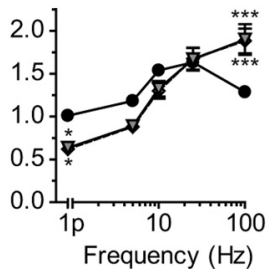

$\beta 3-/-$

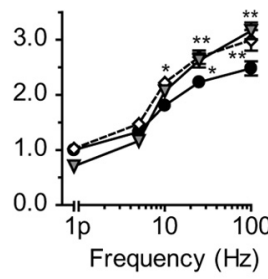

b

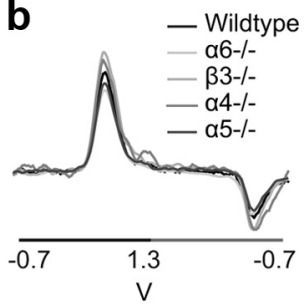

Figure 1. $\alpha 6, \beta 3$, and $\alpha 4$ subunits required for $n A C h R$ regulation of DA release probability in NAc core. $\boldsymbol{a}$, Mean peak $[D A]_{0} \pm$ SEM versus frequency (four pulses) in control (drug-free) conditions (circles), with $\alpha$-CtxMII (diamonds) or with $\alpha$-CtxMII plus $\mathrm{DH} \beta \mathrm{E}$ (triangles), $n=9$. Three-way ANOVA for drug, frequency, and genotype: significant interactions $(p<0.001)$. Drug effects within genotypes: ${ }^{*} p<0.05,{ }^{* *} p<0.01,{ }^{* * *} p<0.001$ (vs control), two-way ANOVA with Bonferroni post hoc $t$ tests. $\boldsymbol{b}$, Typical evoked DA voltammograms (unscaled).

tions for $\alpha 4, \alpha 5, \alpha 6$, or $\beta 3$ subunits we defined the subunit compositions of the $\alpha 4 / \alpha 6 \beta 2^{\star}$ nAChRs that dynamically gate DA release probability in NAc core and in $\mathrm{CPu}$.

\section{Materials and Methods}

Slice preparation and voltammetry. Coronal striatal slices (0.98-1.18 $\mathrm{mm}$ anterior to bregma) (Franklin and Paxinos, 2008), $300 \mu \mathrm{m}$ thick, were prepared using described methods (Exley et al., 2008, 2011) from brains of adult male mice (C57BL/6J strain) of wild-type (Charles River), or $\alpha 6^{-1-}, \alpha 4^{-1-}, \alpha 5^{-1-}$ or $\beta 3^{-1-}$ mice. Knock-out mice have been described previously (Marubio et al., 1999; Champtiaux et al., 2002; Cui et al., 2003; Salas et al., 2003). They have normal gross phenotypes and were backcrossed with a wild-type C57BL/6J line for a minimum of 10 generations (as recommended by the Banbury Conference on Genetic Background in Mice, 1997) to ensure similar genetic backgrounds.

Extracellular dopamine concentration $\left([\mathrm{DA}]_{\mathrm{o}}\right)$ was monitored at $32^{\circ} \mathrm{C}$ using fast-scan cyclic voltammetry with 7-8 $\mu \mathrm{m}$ carbon-fiber microelectrodes (tip length $\sim 50-100 \mu \mathrm{m}$ ) and a Millar voltammeter (Julian Millar, Barts and London School of Medicine and Dentistry, London, UK) as described previously (Exley et al., 2008, 2011). In brief, the scanning voltage was a triangular waveform $(-0.7$ to $+1.3 \mathrm{~V}$ vs $\mathrm{Ag} / \mathrm{AgCl})$ at a scan rate of $800 \mathrm{~V} / \mathrm{s}$, with a frequency of $8 \mathrm{~Hz}$. Evoked electrochemical currents were attributable to DA by potentials for peak oxidation and reduction currents seen for applied DA (+500/600 and $-250 \mathrm{mV}$ respectively) (see Figs. $1 b, 3 b$ ). Electrodes were calibrated post hoc with $2 \mu \mathrm{M} \mathrm{DA}$ in experimental media.

DA release was evoked by a local bipolar concentric electrode $(25 \mu \mathrm{m}$ diameter, Pt/Ir; FHC). Stimulus pulses (200 $\mu$ s duration) were generated at the lowest current $(0.5 \mathrm{~mA})$ that generated maximal DA release with a single pulse. Release was $\mathrm{Ca}^{2+}$ dependent and TTX sensitive (data not shown), and was not modulated by glutamate or GABA antagonists (Threlfell et al., 2010).

Experimental design and analysis. Stimuli were repeated at $2.5 \mathrm{~min}$ intervals to ensure consistent release. Stimuli were either single pulses (1p) or trains of four pulses (4p) at frequencies ranging from "tonic" $(1-10 \mathrm{~Hz})$ to "phasic" burst frequencies $(\geq 15-40 \mathrm{~Hz})$ of DA neurons that signal salient events in vivo (e.g., reward-predicting stimuli) (Schultz, 1986; Hyland et al., 2002; Bayer and Glimcher, 2005). The highest frequency $(100 \mathrm{~Hz})$ is particularly useful for probing changes in DA release probability (Rice and Cragg, 2004; Threlfell et al., 2010). CPu recording sites were located centrally in the dorsal quartile of $\mathrm{CPu}$; those in NAc were ventral to the anterior commissure in the NAc core.
To assess the effects of frequency and drug, data were obtained from a population of sites where frequency and drug were varied at each site (see Figs. 1, 3). To assess the effects of nicotine (see Figs. 2, 4), a simplified protocol of two types of stimuli was used (single pulse or a four-pulse, $100 \mathrm{~Hz}$ train), and data were obtained from multiple recording locations each sampled only once. Data are means \pm SEM, and the sample size, $n$, is the number of observations. The number of animals for each dataset is three or more. Effects of genotype, $\mathrm{nAChR}$ drugs, and/or region during stimuli of varying frequency were analyzed by three-way ANOVA and Holm-Sidak post hoc multiplecomparison $t$ tests. The effects of each nAChR drug during stimuli of varying frequency in a given genotype were subsequently analyzed by two-way ANOVA and Bonferroni post hoc multiple-comparison $t$ tests. Statistical analyses were performed using Sigmaplot11 and GraphPad Prism 4.

Drugs. $\alpha$-conotoxin MII ( $\alpha$-CtxMII) was synthesized as previously (Cartier et al., 1996) and used at concentrations which have no effects at non- $\alpha 6 / \alpha 3$ nAChRs (Cartier et al., 1996) but maximally inhibit the $\alpha$-CtxMIIsensitive component of striatal DA release (Exley et al., 2008, 2011). Deletion of $\alpha 6$ subunits eliminates $\alpha$-CtxMII binding (Champtiaux et al., 2003) and, as expected, eliminated effects of $\alpha$-CtxMII (30-100 nм) on evoked DA release in $\alpha 6^{-1-}$ mice ( $1 \mathrm{p} / 4 \mathrm{p}$ stimuli, data not shown), and thus the effect of $\alpha$-Ctx-MII was not explored further in $\alpha 6^{-1-}$ mice. Nicotine (tartrate) and dihydro- $\beta$-erythroidine (DH $\beta \mathrm{E})$ were from Tocris Bioscience, and other reagents were from Sigma-Aldrich.

\section{Results}

We probed the identities of the striatal $\beta 2^{\star} \mathrm{nAChRs}$ through which endogenous ACh regulates DA transmission in NAc core and in $\mathrm{CPu}$. We assessed the effect of the deletion of subunits $\alpha 4$, $\alpha 5, \alpha 6$, or $\beta 3$ on the regulation of DA release evoked by brief trains of a broad spectrum of frequencies (5-100 Hz). We combined this approach with the application of the $\alpha 6$-selective antagonist $\alpha$-CtxMII and then the broad-spectrum $\beta 2$-antagonist $\mathrm{DH} \beta \mathrm{E}$ to explore the role of first $\alpha 6^{*} \mathrm{nAChRs}$ and subsequently non- $\alpha 6 \mathrm{nAChRs}$ (which in striatum are $\alpha 4^{*} \mathrm{nAChRs}$ ). By thus combining individual subunit deletions with the effects of pharmacological antagonists, we can deduce the nAChRs subunits that are responsible for ACh control of DA release.

In NAc core, in wild-type mice in control (drug-free) conditions, peak evoked extracellular DA concentration ([DA $\left.]_{\mathrm{o}}\right)$ was only weakly sensitive to frequency (Fig. 1a), following a bellshaped curve, as reported previously (Exley et al., 2008, 2011). These observations are consistent with high initial DA release probability and accompanying short-term depression (Rice and Cragg, 2004; Zhang and Sulzer, 2004). In NAc core in wild-type mice as shown previously, $\alpha$-CtxMII (30 nM) reduced $[\mathrm{DA}]_{\mathrm{o}}$ evoked by low frequencies $(\leq 10 \mathrm{~Hz})$ but promoted frequency sensitivity, which increased $[\mathrm{DA}]_{\mathrm{o}}$ evoked by high frequency $(100$ $\mathrm{Hz}$ ) (Exley et al., 2008, 2011). Subsequent application of the broad-spectrum $\mathrm{nAChR}$ antagonist $\mathrm{DH} \beta \mathrm{E}(1 \mu \mathrm{M})$ did not further modify release (Fig. 1a), consistent with the dominant role of $\alpha 6 \beta 2^{*}$-nAChRs in NAc shown previously (Exley et al., 2008, 2011). In mice with deletions of $\alpha 6, \beta 3$, or $\alpha 4$ subunits, peak evoked $[\mathrm{DA}]_{\mathrm{o}}$ values in NAc core were modified compared with wild type (three-way ANOVAs, genotype $\times$ frequency $\times$ drug treatment, pairwise interactions, $p<0.001)$. Release showed 
greater frequency sensitivity even in drugfree conditions (two-way ANOVA, frequency $\times$ genotype, $p<0.001)$. This was due to the significant loss of nAChR control of DA release: the effects of $\alpha$-CtxMII and $\mathrm{DH} \beta \mathrm{E}$ were markedly attenuated, causing only slight additional changes to [DA ] (Fig. $1 a$ ). In $\alpha 5$ nulls by contrast, the frequency sensitivity of DA release in drug-free conditions followed a bellshaped curve unlike the other null mice. $\alpha$-CtxMII strongly increased frequency sensitivity with bidirectional effects on evoked $[\mathrm{DA}]_{\mathrm{o}}$, as seen in wild-type mice (Fig. 1a). These data suggest that the $\beta 2^{*}$ $\mathrm{nAChRs}$ regulating DA release in NAc core depend strongly on $\alpha 6, \alpha 4$, and $\beta 3$ subunits, but less so on $\alpha 5$ subunits, suggesting that the $\alpha 4 \alpha 6 \alpha \beta 2 \beta 3 \mathrm{nAChR}$ in NAc core is the dominant $n A C h R$. The minor effects of $\mathrm{nAChR}$ antagonists seen in $\alpha 6-, \beta 3-$, or $\alpha 4$-null mice suggest only minor roles for any $\alpha 4$ (non- $\alpha 6)$, $\alpha 6($ non $\beta 3$ ), or $\alpha 6$ (non- $\alpha 4$ ) nAChRs.

We tested in NAc core whether the effects of nicotine on DA release showed similar subunit dependence, using a simplified protocol to compare the ratio of DA release by a single pulse versus $4 \mathrm{p}$ at $100 \mathrm{~Hz}$, for which nAChR effects are most marked (Exley et al., 2008, 2011). Nicotine (500 nM) has been shown previously to desensitize $\beta 2^{*} \mathrm{nAChRs}$ with the same outcome as $\mathrm{nAChR}$ antagonism (Zhou et al., 2001; Rice and Cragg, 2004; Zhang and Sulzer, 2004): consistent with these data, nicotine in wild types reduced $1 \mathrm{p}$ release, which promoted the sensitivity of $[\mathrm{DA}]_{\mathrm{o}}$ to activity (4p/100 Hz vs 1p) (Fig. 2). However, in $\alpha 6-, \alpha 4-$, or $\beta 3$-nulls, but not $\alpha 5$-nulls, the ratios of [DA $]_{\mathrm{o}}$ evoked by $4 \mathrm{p}$ $(100 \mathrm{~Hz})$ versus $1 \mathrm{p}$ were elevated compared with wild-type mice in drug-free conditions (Fig. $2 b$, as seen in experiments for Fig. 1), and were not enhanced further by nicotine $(500 \mathrm{nM})$. This ratio was enhanced by nicotine in $\alpha 5$-nulls (Fig. 2).

We explored the nAChR subunits responsible for ACh control of DA release in $\mathrm{CPu}$. In $\mathrm{CPu}$ wild types, as in NAc, $[\mathrm{DA}]_{\text {o }}$ was only weakly sensitive to frequency (Fig. 3a), following a bell-shaped curve, as reported previously (Exley et al., 2008). However, there were key differences to NAc core in effects of genotypes and nAChR drugs (three-way ANOVAs: region $\times$ frequency $\times$ genotype interactions, $p<0.001$; region $X$ frequency $\times$ drug treatment interactions in wild types, $p<0.01)$. In $\mathrm{CPu}$, unlike in NAc, $\alpha 4($ non- $\alpha 6) \beta 2^{*}$ nAChRs strongly govern DA release probability, and $\alpha 6^{*}$ nAChRs appear to have a minor role (Exley et al., 2008). As shown previously, in wild types, $\alpha$-CtxMII (30 nM) had only small effect compared with $\mathrm{DH} \beta \mathrm{E}(1 \mu \mathrm{M})$ on frequency sensitivity of release (Fig. $3 a$ ). Surprisingly however, subunit deletion had no significant effects on the net $\mathrm{nAChR}$ regulation of fre-

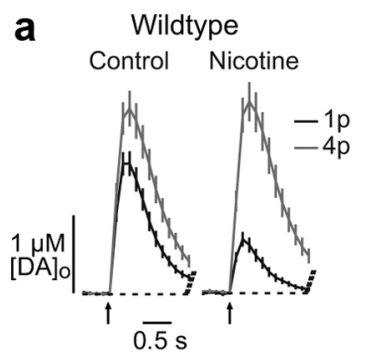

$\alpha 4-/-$

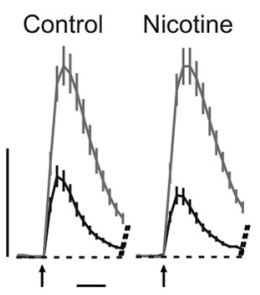

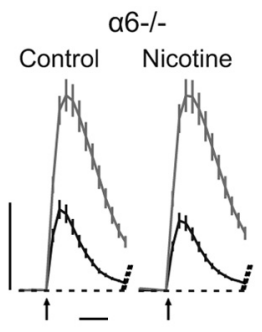

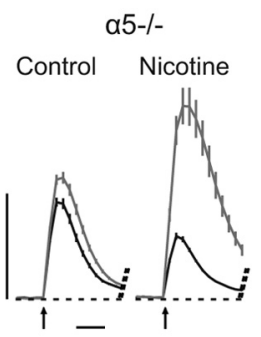

b Wildtype $\square$ a6- $/-$ 口ß3-/- $\square \alpha 4-/-\square \alpha 5-/$

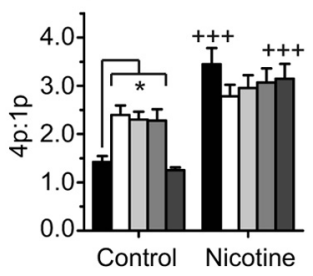

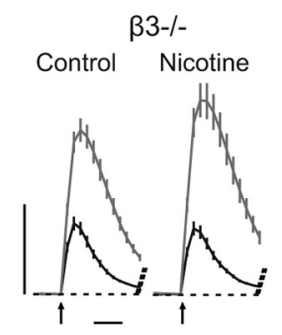

Figure 2. Nicotine modulation of DA release probability lost after deletion of $\alpha 6, \beta 3$, and $\alpha 4$ subunits. $\boldsymbol{a}$, Mean profiles of $[D A]_{0} \pm$ SEM evoked by $1 \mathrm{p}$ or $4 \mathrm{p} / 100 \mathrm{~Hz}$ in NAc core in drug-free controls or nicotine $(500 \mathrm{~nm}), n=16-32$. $\boldsymbol{b}$, Ratios of $[D A]_{0}$ evoked by $4 p / 100 \mathrm{~Hz}$ versus $1 p$ in controls and nicotine (500 nm). Enhanced $4 p / 1 p$ release in $\alpha 6^{-l-}, \beta 3^{-/-}$, and $\alpha 4^{-I-}$ versus wild type is not modified by nicotine. Two-way ANOVA with Bonferroni post hoc $t$ tests. ${ }^{*} p<0.01$ (vs wild type), ${ }^{++} p<0.001$ (nicotine vs control).

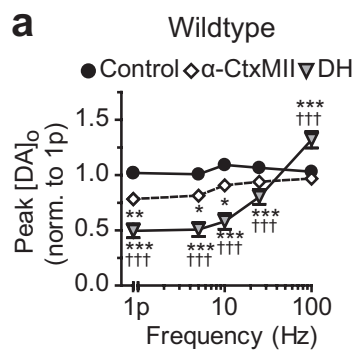

a4-/-

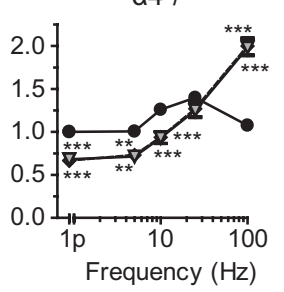

$\alpha 6-/-$

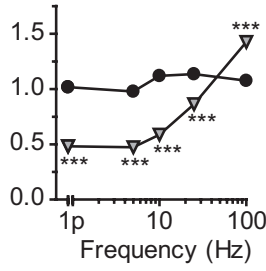

a5-/-

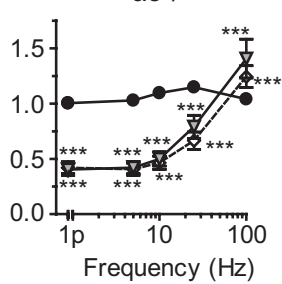

$\beta 3-/-$

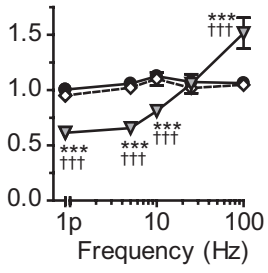

b

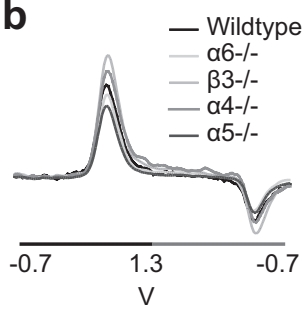

Figure 3. Versatility in subunit sufficiency but critical role for $\alpha 5$ subunits in $\mathrm{nAChR}$ regulation of DA release in CPu. $\boldsymbol{a}$, Mean peak $[\mathrm{DA}]_{0} \pm$ SEM versus frequency (4p) in control conditions (circles), with $\alpha$-CtxMII (diamonds) or $\alpha$-CtxMII with DH $\beta \mathrm{E}$ (triangles), $n=9$. Three-way ANOVA for drug, frequency, and genotype: significant interactions $(p<0.001)$. Symbols indicate drug effects within genotypes: ${ }^{*} p<0.05,{ }^{* *} p<0.01,{ }^{* * *} p<0.001$ (vs control); ${ }^{\mathrm{ttt}} p<0.001$ (vs $\alpha$-CtxMII), two-way ANOVA with Bonferroni post hoc $t$ test. $\boldsymbol{b}$, Typical evoked DA voltammograms (unscaled).

quency sensitivity of DA release (two-way ANOVA, frequency $X$ genotype, $p>0.05$ ). In drug-free conditions across genotypes, frequency sensitivity remained limited and was significantly promoted by the broad-spectrum antagonist $\mathrm{DH} \beta \mathrm{E}$ (Fig. 3a). However, the effects of $\alpha$-CtxMII varied with genotype (pairwise post hoc $t$ tests, $p<0.001$ ), revealing roles for key individual subunits and substitution of subtypes that maintain net nAChR control after deletion. Deletion of $\alpha 6$ subunits eliminated $\alpha$-CtxMII effects (data not shown) and indicated that non- $\alpha 6$ nAChRs (i.e., $\alpha 4^{\star}$ nAChRs) are entirely sufficient to support $\mathrm{nAChR}$ control of DA. Deletion of $\beta 3$ subunits, however, eliminated the modest $\alpha$-CtxMII effects (Fig. 3a), indicating that the 


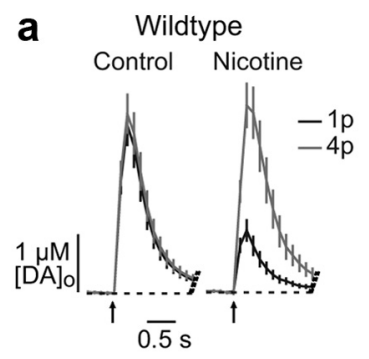

$\alpha 4-/-$

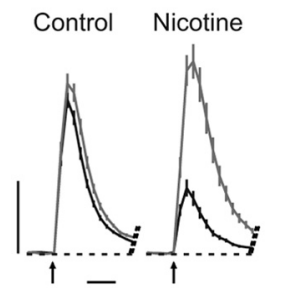

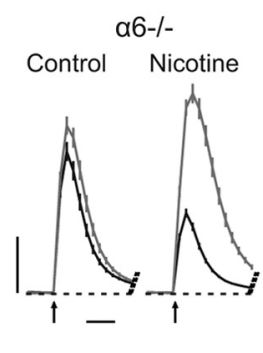

a5-/-
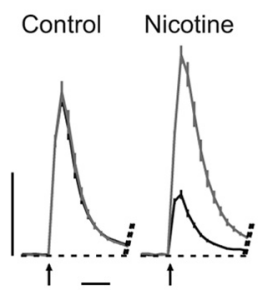

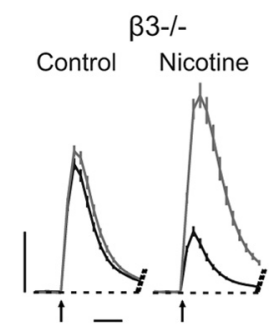

b $\quad$ Wildtype $\square \alpha 6-/-$ $\square \beta 3-/-\square \alpha 4-/-\square \alpha 5-/-$

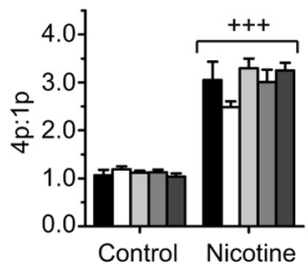

Figure 4. Nicotine modulation of DA release probability in CPu after subunit deletion. $\boldsymbol{a}$, Mean profiles of $[D A]_{0} \pm S E M$ evoked by $1 \mathrm{p}$ or $4 \mathrm{p} / 100 \mathrm{~Hz}$ in CPu. Nicotine-mediated changes in $[\mathrm{DA}]_{0}$ were not affected by subunit deletion, $n=16-32$. $\boldsymbol{b}$, Ratios of $[D A]_{0}$ evoked by $4 p / 100 \mathrm{~Hz}$ versus $1 p$ in control or nicotine $(500 \mathrm{~nm})$ where subunit deletion did not alter the $4 p / 1 \mathrm{p}$ release from wild type. Two-way ANOVA with Bonferroni post hoc $t$ tests. ${ }^{+++} p<0.001$ (nicotine vs control).

minor $\alpha 6$-dependent component seen in wild types results from $\alpha 6 \beta 3(\beta 2)^{\star}$ nAChRs. After deletion of either $\alpha 4$ or $\alpha 5$ subunits, the substantial remaining nAChR control was entirely $\alpha$-CtxMII sensitive (Fig. 3a). These data indicate first that while $\alpha 6 \mathrm{nAChRs}$ do not normally play a major role, the $\alpha 6 \beta 3(\beta 2) \mathrm{nAChRs}$ can be functional in $\mathrm{CPu}$ under appropriate conditions, substituting for the normally dominant $\alpha 4$ (non- $\alpha 6) \beta 2^{*}$ nAChRs. Second, they indicate that normally dominant $\alpha 4 \beta 2^{\star}$ control depends critically on the availability of $\alpha 5$ subunits, presumably through the $\alpha 4 \alpha 5 \beta 2$ nAChRs, which are known to be present (Gotti et al., 2010).

Subunit knockout in CPu had similar impact on the net effects of nicotine. In all knockouts, the ratios of $[\mathrm{DA}]_{\mathrm{o}}$ evoked by $4 \mathrm{p}$ $(100 \mathrm{~Hz})$ versus $1 \mathrm{p}$ were not different compared with wild types in drug-free conditions, and were significantly enhanced by nicotine (500 nM) (Fig. 4).

\section{Discussion}

We show that control of DA transmission by ACh and nicotine in striatum is dominated by mutually exclusive populations of nAChRs: $\alpha 4 \alpha 6 \beta 2 \beta 3 \mathrm{nAChRs}$ in NAc core and $\alpha 4 \alpha 5 \beta 2 \mathrm{nAChRs}$ in dorsal $\mathrm{CPu}$. We show also a difference in the necessity versus sufficiency for $\alpha 4, \alpha 5, \alpha 6$, or $\beta 3$ subunits in the $\mathrm{nAChR}$ regulation of DA release in $\mathrm{CPu}$ versus NAc core.

These data corroborate findings that $\alpha 4 \alpha 6 \beta 2^{*} \mathrm{nAChRs}$ are necessary for $\mathrm{ACh}$ and nicotine to regulate $\mathrm{DA}$ release probability in NAc (Exley et al., 2011), and reveal further that this control codepends on $\beta 3$ subunits, through presumably $\alpha 4 \alpha 6 \beta 2 \beta 3$ nAChRs. We find evidence for only minor roles for other subtypes after subunit deletions [i.e., the $\alpha 4 / \alpha 5$ (non- $\alpha 6$ ), $\alpha 6$ (non $\beta 3$ ), or $\alpha 6$ (non- $\alpha 4$ ) nAChRs], but, given the $\alpha$-CtxMII sensitivity of release under normal conditions, only the $\alpha 6^{*}$ $n A C h R s$ of these could be expected to contribute, if any. A role for $\alpha 4 \alpha 6 \beta 2 \beta 3 \mathrm{nAChRs}$ in NAc core is supported by the presence of this receptor within striatum (Gotti et al., 2010) and by reductions in $\alpha$-CtxMII-sensitive striatal DA release and nAChR binding after $\alpha 4$ or $\beta 3$ subunit deletion (Champtiaux et al., 2002; Salminen et al., 2005, 2007). The dominance of this nAChR type is, however. slightly surprising given that it has been suggested to account for only $14 \%$ of nAChRs here (Gotti et al., 2010). This disparity emphasizes that it is difficult to infer the function of $\mathrm{nAChR}$ subtypes in regulating DA transmission from $\mathrm{nAChR}$ expression levels alone (Exley et al., 2008). It could be argued that the protocol used here, which drives DA release in slices during discrete, subsecond but synchronous activation of DA and ACh release, better demonstrates the function of particular nAChR subtypes over others. However, the same protocol in the adjacent striatal region, $\mathrm{CPu}$, reveals a different subunit dependence.

In dorsal $\mathrm{CPu}$, we show that, in contrast to NAc core, no single type of subunit (of $\alpha 4-\alpha 6, \beta 3$ ) is necessary to support $\mathrm{nAChR}$ regulation of DA release by $\mathrm{ACh} /$ nicotine. Rather, alternative nAChR subtypes become sufficient. We show in particular after deletion of individual subunits, that either $\alpha 4$ (non- $\alpha 6$ ) or $\alpha 6$ (non- $\alpha 4$ ) nAChRs can operate and be sufficient, that $\alpha 6$ function requires $\beta 3$, and that $\alpha 4$ function critically requires $\alpha 5$. Together, these data indicate that the $\mathrm{nAChR}$ subtypes that govern DA release probability in $\mathrm{CPu}$ are substitutable, unlike in NAc core, and that while $\alpha 6$ (non$\alpha 4) \beta 2 \beta 3$-nAChRs can regulate DA release, DA in CPu is normally dominantly regulated by $\alpha 4$ (non- $\alpha 6$ ) $\beta 2$-nAChRs, which require an $\alpha 5$ subunit (i.e., $\alpha 4 \alpha 5 \beta 2$ nAChRs).

Variation between $\mathrm{CPu}$ and NAc core in substitutability of alternative $\mathrm{nAChR}$ subtypes after individual subunit deletion, is likely to occur at the level of $\mathrm{nAChR}$ formation and/or functional coupling rather than through compensatory upregulation in expression levels of alternate subunits, because there are no reported changes in transcript levels of alternate subunits after deletion of individual subunits (Champtiaux et al., 2002, 2003; Cui et al., 2003; Salas et al., 2003; Grady et al., 2007). Variation in such mechanisms between $\mathrm{CPu}$ and NAc is not altogether surprising given that these axons derive from different parent DA neurons, in substantia nigra pars compacta $(\mathrm{SNc})$ versus ventral tegmental area (VTA), respectively. However, the mechanisms that could differentiate receptor trafficking and functional coupling in $\mathrm{CPu}$ versus NAc have yet to be identified. We have, however, previously shown that after deletion of either $\alpha 4$ or $\alpha 6$ subunits, the lack of "rescue" of net nAChR control of DA release by other subunits in NAc is not due to ACh levels being below some threshold that is required for $\mathrm{nAChR}$ activation: inhibitors of ACh-esterase, which promote ACh levels, do not restore any nAChR control by remaining subunits (Exley et al., 2011).

In striatum, the $\alpha 5$ subunit has been shown to form a receptor with $\alpha 4$ and $\beta 2$ subunits of similar properties to the "high sensitivity" $\alpha 4 \beta 2$ nAChR (Grady et al., 2010). It would not have been predicted, however, that the $\alpha 5 \alpha 4 \beta 2 \mathrm{nAChR}$ accounts for the entire population of the $\alpha$-CtxMII-resistant regulation of DA release in $\mathrm{CPu}$, as shown here: coimmunoprecipitation studies suggest that $\sim 40 \%$ of non- $\alpha 6$ (i.e., $\alpha 4$ ) nAChRs do not contain $\alpha 5$ (Gotti et al., 2010).

In conclusion, we have identified that discrete nAChR populations govern the regulation of DA release probability in NAc core versus $\mathrm{CPu}$. We reveal that $\alpha 5$ subunits are essential to $\alpha 4^{\star} \mathrm{nAChR}$ function in $\mathrm{CPu}$ but not in NAc core, regions respectively associated with instrumental and habitual behaviors versus pavlovian associa- 
tions. The function of $\alpha 5^{\star}$ nAChRs in regulating activity in DA neurons within VTA or SNc is not yet resolved, but the functions of nAChRs we show at axon terminals suggest that modifications to $\alpha 5$ function might modify the risk of nicotine dependence through a dysregulation of behaviors encoded at the level of dorsal striatum.

\section{References}

Banbury Conference on Genetic Background in Mice (1997) Mutant mice and neuroscience: recommendations concerning genetic background. Neuron 19:755-759.

Bayer HM, Glimcher PW (2005) Midbrain dopamine neurons encode a quantitative reward prediction error signal. Neuron 47:129-141.

Bierut LJ (2010) Convergence of genetic findings for nicotine dependence and smoking related diseases with chromosome 15q24-25. Trends Pharmacol Sci 31:46-51.

Cartier GE, Yoshikami D, Gray WR, Luo S, Olivera BM, McIntosh JM (1996) A new alpha-conotoxin which targets alpha3beta2 nicotinic acetylcholine receptors. J Biol Chem 271:7522-7528.

Champtiaux N, Han ZY, Bessis A, Rossi FM, Zoli M, Marubio L, McIntosh JM, Changeux JP (2002) Distribution and pharmacology of alpha 6-containing nicotinic acetylcholine receptors analyzed with mutant mice. J Neurosci 22:1208-1217.

Champtiaux N, Gotti C, Cordero-Erausquin M, David DJ, Przybylski C, Léna C, Clementi F, Moretti M, Rossi FM, Le Novère N, McIntosh JM, Gardier AM, Changeux JP (2003) Subunit composition of functional nicotinic receptors in dopaminergic neurons investigated with knock-out mice. J Neurosci 23:7820-7829.

Cui C, Booker TK, Allen RS, Grady SR, Whiteaker P, Marks MJ, Salminen O, Tritto T, Butt CM, Allen WR, Stitzel JA, McIntosh JM, Boulter J, Collins AC, Heinemann SF (2003) The beta3 nicotinic receptor subunit: a component of alpha-conotoxin MII-binding nicotinic acetylcholine receptors that modulate dopamine release and related behaviors. J Neurosci 23:11045-11053.

Exley R, Cragg SJ (2008) Presynaptic nicotinic receptors: a dynamic and diverse cholinergic filter of striatal dopamine neurotransmission. $\mathrm{Br} \mathrm{J}$ Pharmacol 153 [Suppl 1]:S283-S297.

Exley R, Clements MA, Hartung H, McIntosh JM, Cragg SJ (2008) Alpha6containing nicotinic acetylcholine receptors dominate the nicotine control of dopamine neurotransmission in nucleus accumbens. Neuropsychopharmacology 33:2158-2166.

Exley R, Maubourguet N, David V, Eddine R, Evrard A, Pons S, Marti F, Threlfell S, Cazala P, McIntosh JM, Changeux JP, Maskos U, Cragg SJ, Faure P (2011) Distinct contributions of nicotinic acetylcholine receptor subunit alpha4 and subunit alpha6 to the reinforcing effects of nicotine. Proc Natl Acad Sci U S A 108:7577-7582.

Fowler CD, Lu Q, Johnson PM, Marks MJ, Kenny PJ (2011) Habenular alpha5 nicotinic receptor subunit signalling controls nicotine intake. Nature 471:597-601.

Frahm S, Slimak MA, Ferrarese L, Santos-Torres J, Antolin-Fontes B, Auer S, Filkin S, Pons S, Fontaine JF, Tsetlin V, Maskos U, Ibañez-Tallon I (2011) Aversion to nicotine is regulated by the balanced activity of beta 4 and alpha5 nicotinic receptor subunits in the medial habenula. Neuron 70:522-535.

Franklin KBJ, Paxinos G (2008) The mouse brain in stereotaxic coordinates, Ed 3. New York: Elsevier.

Gotti C, Guiducci S, Tedesco V, Corbioli S, Zanetti L, Moretti M, Zanardi A, Rimondini R, Mugnaini M, Clementi F, Chiamulera C, Zoli M (2010) Nicotinic acetylcholine receptors in the mesolimbic pathway: primary role of ventral tegmental area $\alpha 6 \beta 2^{*}$ receptors in mediating systemic nicotine effects on dopamine release, locomotion, and reinforcement. J Neurosci 30:5311-5325.

Grady SR, Salminen O, Laverty DC, Whiteaker P, McIntosh JM, Collins AC, Marks MJ (2007) The subtypes of nicotinic acetylcholine receptors on dopaminergic terminals of mouse striatum. Biochem Pharmacol 74:1235-1246.

Grady SR, Salminen O, McIntosh JM, Marks MJ, Collins AC (2010) Mouse striatal dopamine nerve terminals express alpha4alpha5beta2 and two stoichiometric forms of alpha4beta2*-nicotinic acetylcholine receptors. J Mol Neurosci 40:91-95.

Hyland BI, Reynolds JN, Hay J, Perk CG, Miller R (2002) Firing modes of midbrain dopamine cells in the freely moving rat. Neuroscience 114:475-492.
Kuryatov A, Berrettini W, Lindstrom J (2011) Acetylcholine receptor (AChR) alpha5 subunit variant associated with risk for nicotine dependence and lung cancer reduces (alpha4beta2)alpha5 AChR function. Mol Pharmacol 79:119-125.

Marubio LM, del Mar Arroyo-Jimenez M, Cordero-Erausquin M, Léna C, Le Novère N, de Kerchove d'Exaerde A, Huchet M, Damaj MI, Changeux JP (1999) Reduced antinociception in mice lacking neuronal nicotinic receptor subunits. Nature 398:805-810.

Maskos U, Molles BE, Pons S, Besson M, Guiard BP, Guilloux JP, Evrard A, Cazala P, Cormier A, Mameli-Engvall M, Dufour N, Cloëz-Tayarani I, Bemelmans AP, Mallet J, Gardier AM, David V, Faure P, Granon S, Changeux JP (2005) Nicotine reinforcement and cognition restored by targeted expression of nicotinic receptors. Nature 436:103-107.

Matsumoto M, Hikosaka O (2009) Two types of dopamine neuron distinctly convey positive and negative motivational signals. Nature 459:837-841.

Picciotto MR, Zoli M, Rimondini R, Léna C, Marubio LM, Pich EM, Fuxe K, Changeux JP (1998) Acetylcholine receptors containing the beta2 subunit are involved in the reinforcing properties of nicotine. Nature 391:173-177.

Pons S, Fattore L, Cossu G, Tolu S, Porcu E, McIntosh JM, Changeux JP, Maskos U, Fratta W (2008) Crucial role of $\alpha 4$ and $\alpha 6$ nicotinic acetylcholine receptor subunits from ventral tegmental area in systemic nicotine self-administration. J Neurosci 28:12318-12327.

Rice ME, Cragg SJ (2004) Nicotine amplifies reward-related dopamine signals in striatum. Nat Neurosci 7:583-584.

Saccone NL, Saccone SF, Hinrichs AL, Stitzel JA, Duan W, Pergadia ML, Agrawal A, Breslau N, Grucza RA, Hatsukami D, Johnson EO, Madden PA, Swan GE, Wang JC, Goate AM, Rice JP, Bierut LJ (2009) Multiple distinct risk loci for nicotine dependence identified by dense coverage of the complete family of nicotinic receptor subunit (CHRN) genes. Am J Med Genet B Neuropsychiatr Genet 150B:453-466.

Salas R, Orr-Urtreger A, Broide RS, Beaudet A, Paylor R, De Biasi M (2003) The nicotinic acetylcholine receptor subunit alpha 5 mediates short-term effects of nicotine in vivo. Mol Pharmacol 63:1059-1066.

Salminen O, Whiteaker P, Grady SR, Collins AC, McIntosh JM, Marks MJ (2005) The subunit composition and pharmacology of alpha-conotoxin MII-binding nicotinic acetylcholine receptors studied by a novel membrane-binding assay. Neuropharmacology 48:696-705.

Salminen O, Drapeau JA, McIntosh JM, Collins AC, Marks MJ, Grady SR (2007) Pharmacology of \{alpha\}-conotoxin MII-sensitive subtypes of nicotinic acetylcholine receptors isolated by breeding of null mutant mice. Mol Pharmacol 71:1563-1571.

Schultz W (1986) Responses of midbrain dopamine neurons to behavioral trigger stimuli in the monkey. J Neurophysiol 56:1439-1461.

Schultz W (1998) Predictive reward signal of dopamine neurons. J Neurophysiol 80:1-27.

Thorgeirsson TE, Geller F, Sulem P, Rafnar T, Wiste A, Magnusson KP, Manolescu A, Thorleifsson G, Stefansson H, Ingason A, Stacey SN, Bergthorsson JT, Thorlacius S, Gudmondsson J, Johsson T, Jakobsdottir M, Saemundsdottir J, Olafsdottir O, Gudmundsson LJ, Bjornsdottir G, et al (2008) A variant associated with nicotine dependence, lung cancer and peripheral arterial disease. Nature 452:638-642.

Threlfell S, Clements MA, Khodai T, Pienaar IS, Exley R, Wess J, Cragg SJ (2010) Striatal muscarinic receptors promote activity dependence of dopamine transmission via distinct receptor subtypes on cholinergic interneurons in ventral versus dorsal striatum. J Neurosci 30:3398-3408.

Tumkosit P, Kuryatov A, Luo J, Lindstrom J (2006) Beta3 subunits promote expression and nicotine-induced up-regulation of human nicotinic alpha6 $6^{*}$ nicotinic acetylcholine receptors expressed in transfected cell lines. Mol Pharmacol 70:1358-1368.

Wang JC, Cruchaga C, Saccone NL, Bertelsen S, Liu P, Budde JP, Duan W, Fox L, Grucza RA, Kern J, Mayo K, Reyes O, Rice J, Saccone SF, Spiegel N, Steinbach JH, Stitzel JA, Anderson MW, You M, Stevens VL, et al (2009) Risk for nicotine dependence and lung cancer is conferred by mRNA expression levels and amino acid change in CHRNA5. Hum Mol Genet 18:3125-3135.

Zhang H, Sulzer D (2004) Frequency-dependent modulation of dopamine release by nicotine. Nat Neurosci 7:581-582.

Zhou FM, Liang Y, Dani JA (2001) Endogenous nicotinic cholinergic activity regulates dopamine release in the striatum. Nat Neurosci 4:1224-1229. 